\section{Lutas Periféricas na Pandemia}

Peripheral Fights in the Pandemic

Kessis Sena

Universidade de São Paulo. Faculdade de Filosofia, Letras e Ciências Humanas.

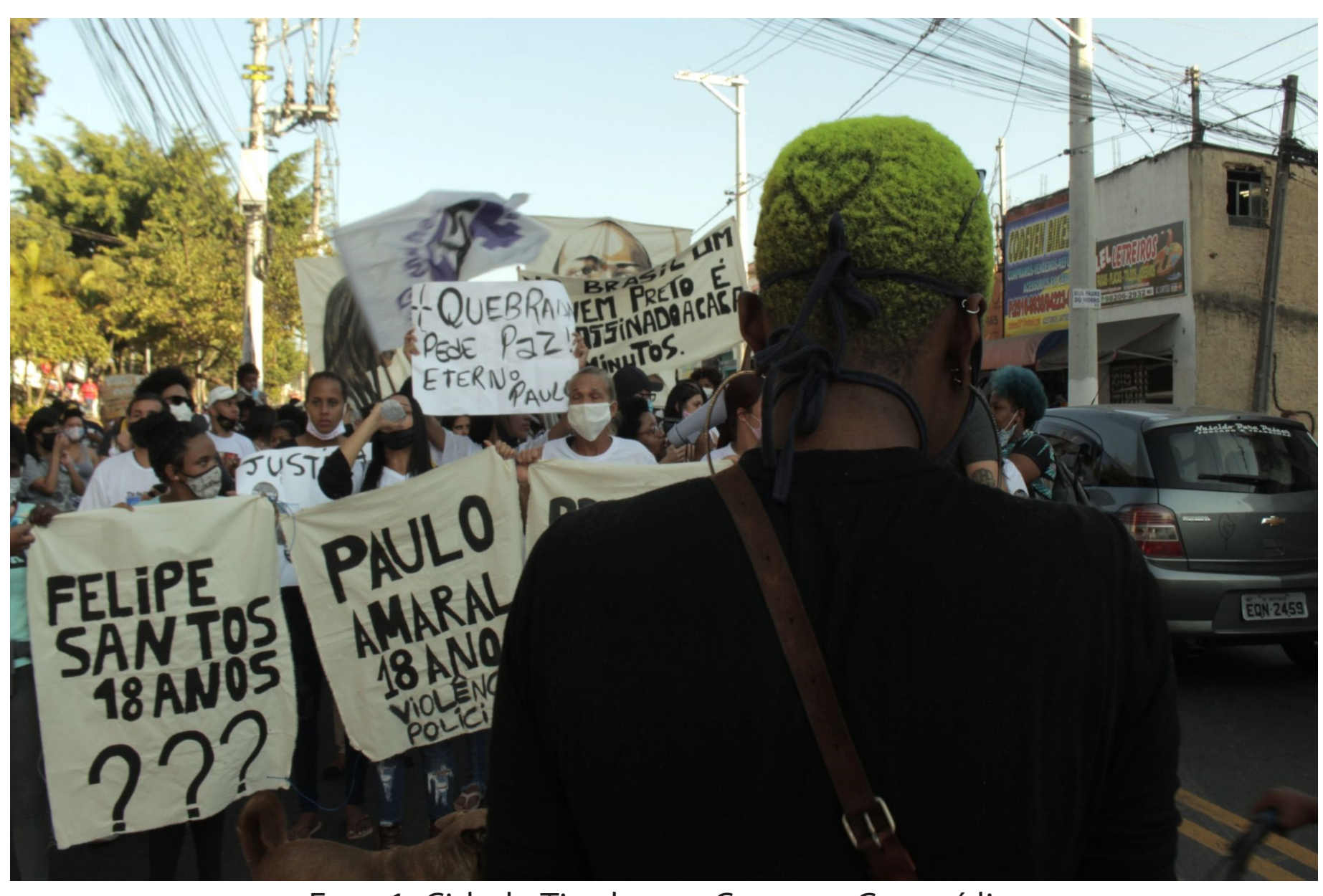

Foto 1: Cidade Tiradentes Contra o Genocídio

Registros de manifestações do povo periférico para produção de um curtadocumentário chamado "Covid na Favela", realizado pela produtora independente Igarapé, disponível no YouTube e no Instagram @igarape.filmes.

O documentário "Covid na Favela", realizado pela produtora independente Igarapé, retrata as denúncias do povo periférico, assim como parte de sua organização para minimizar os impactos econômicos e sociais da pandemia. Gravado em São Paulo e em Belo Horizonte, foi finalizado em janeiro de 2021 e fez parte da programação oficial da sexta edição do festival de cinema Cine Tamoio, de São Gonçalo.

O documentário registrou movimentação da população periférica em resposta ao aumento da violência policial durante a pandemia em atos como o de Cidade Tiradentes contra o Genocídio; Justiça por Guilherme, na Zona Sul de São Paulo, além da movimentação em resposta à morte de George Floyd, nos Estados Unidos. São lembradas também as violações de direitos humanos ocorridas no Brasil similares ao caso de George Floyd, como o caso do estudante Pedro Henrique de Oliveira Gonzaga, de 19 anos, estrangulado no Extra da Barra da Tijuca no período anterior à pandemia, entre outros casos de racismo estrutural.

O documentário acompanha a movimentação e organização da favela de Paraisópolis no combate à fome em sua captação e entrega de cestas básicas para a comunidade. A questão da moradia é citada por meio dos diálogos estabelecidos entre a população de rua por meio do movimento POP RUA, de São Paulo, e pelo protesto por moradia realizado na Favela do Jaguaré, na Zona Oeste de São Paulo, organizado pelo MLB - Movimento de Luta nos Bairros e Favelas. Em Belo Horizonte, foram registradas denúncias em resposta aos alagamentos comuns nos territórios em que se assentam populações periféricas ao lado de grandes obras realizadas pelo estado em regiões centrais, como ocorrido no Vale do Anhangabaú, reflexos da campanha "O Brasil não pode parar".

O Breque dos Apps, primeira paralisação nacional organizada por entregadores de aplicativos, é citado ao retratar a formação de novos sujeitos revolucionários frutos das reformas de sucateamento dos direitos trabalhistas e formação do precariado. Ao lado dos trabalhadores da saúde e da limpeza, protagonizaram as atividades essenciais na manutenção do distanciamento físico por sua função de assegurar que 


\section{parte da população mantenha-se em casa.}

Sinopse do curta-documentário: As favelas, corpos onde habitam múltiplas espacialidades, evidenciam as contradições das medidas sanitárias para conter o avanço da pandemia no Brasil. A necessidade de ir ao trabalho ou a impossibilidade do isolamento pelas condições de moradia coloca em risco a população periférica no enfrentamento à pandemia. A situação das favelas, entretanto, não é restrita ao Brasil ou à América Latina. No processo de globalização da economia, encontramos favelas em diversas geografias que vivem na crise do Trabalho do século XXI a formação de novos sujeitos revolucionários.

\section{CIDADE TIRADENTES CONTRA O GENOCÍDIO, 04 de Julho de 2020}

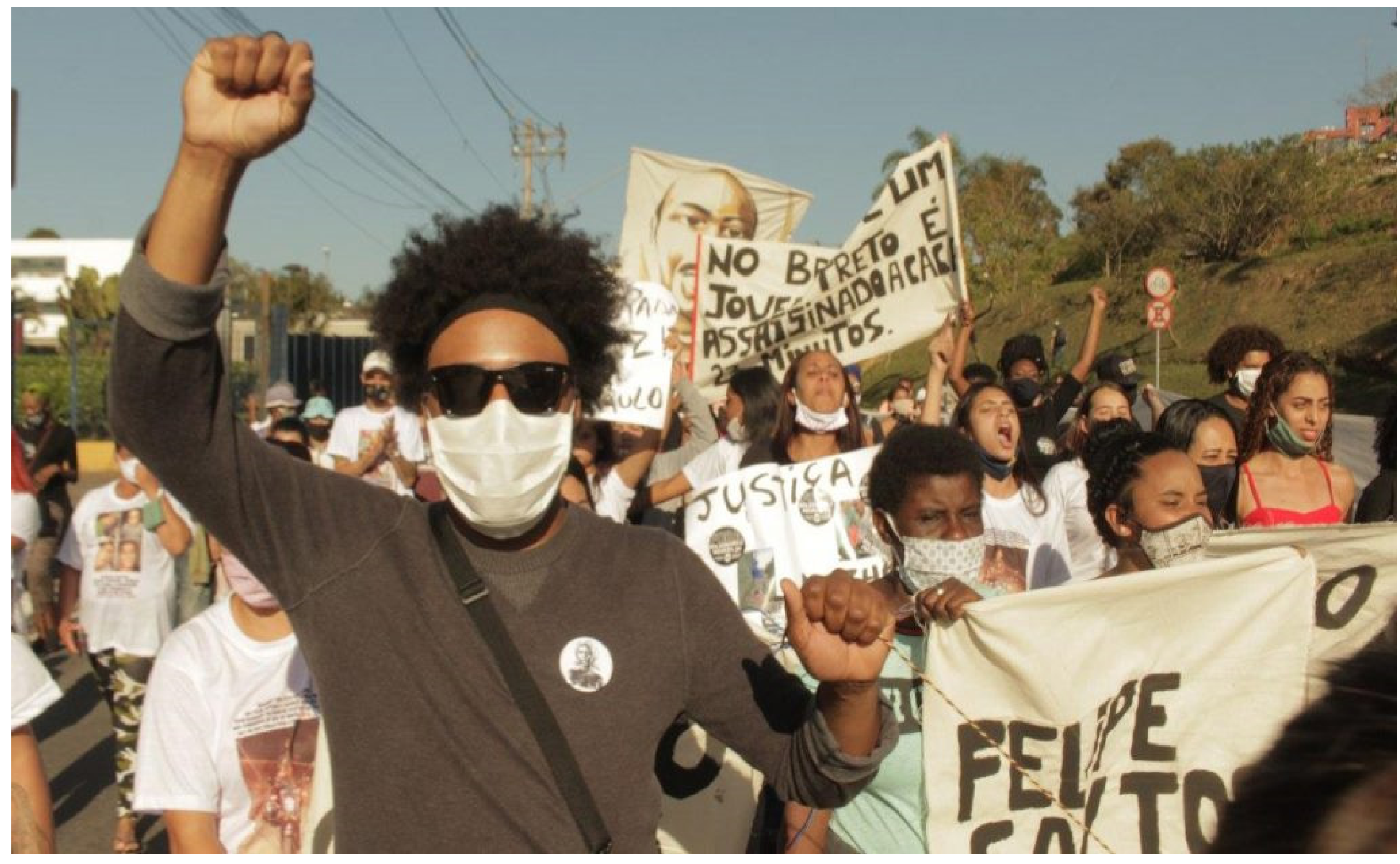

Foto 2: Cidade Tiradentes Contra o Genocídio 
Na tarde de 04 de julho de 2020, a periferia saiu às ruas em denúncia da necropolítica na Cidade Tiradentes, Zona Leste de São Paulo. Cidade Tiradentes é o bairro onde se morre mais cedo em São Paulo: a expectativa de vida é de apenas 57 anos, em média 23 anos a menos do que no bairro de Moema, em SP, onde a expectativa alcança 80 anos, segundo o Mapa das Desigualdades de 2019.

$\mathrm{O}$ ato em protesto pelas mortes de cinco jovens por violência policial, vítimas anteriores e simultâneas à pandemia, ocorreu em meio à disseminação do Covid-19 e demonstra como a população periférica segue sem opções de manter o isolamento social adequado ou respeitar normas de segurança para diminuir as probabilidades de contágio em conflito com a presença e com a ausência do estado.

A ausência se expressa na falta de políticas públicas adequadas à realidade dos moradores de favelas e bairros periféricos; a presença, por sua vez, por meio da força policial que se exerce em repressão, sequestros, torturas e mortes, como as dos cinco jovens: Paulo Gabriel, Leonardo Monteiro dos Santos, Igor Bernardo dos Santos, Felipe Santos e Brayam Ferreira, todos com idade entre 16 e 18 anos. Pesquisas revelam aumento de mortes por violência policial durante a pandemia, de modo que a população segue em risco pela bala e pelo vírus.

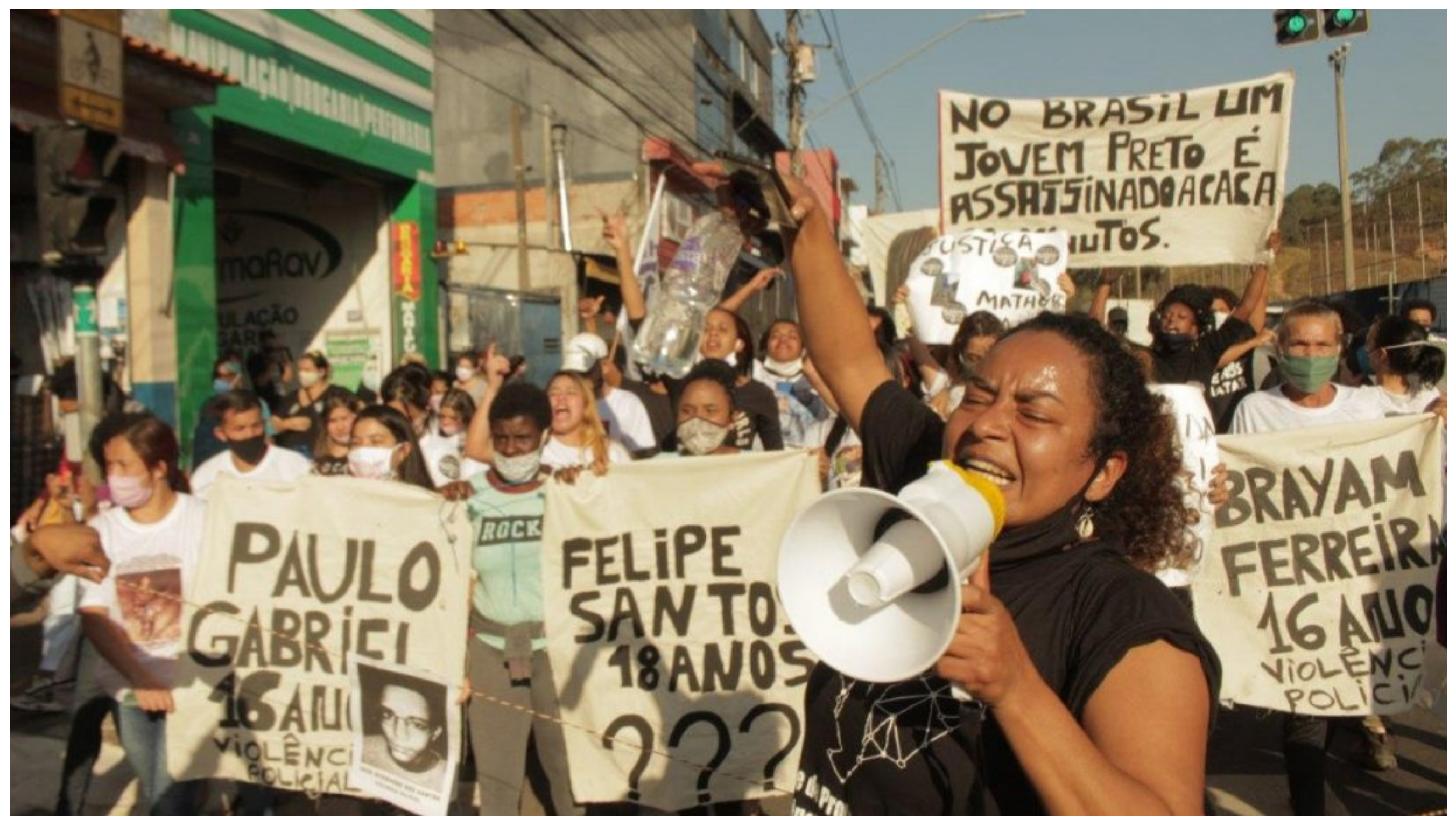

Foto 3 : Cidade Tiradentes Contra o Genocídio 


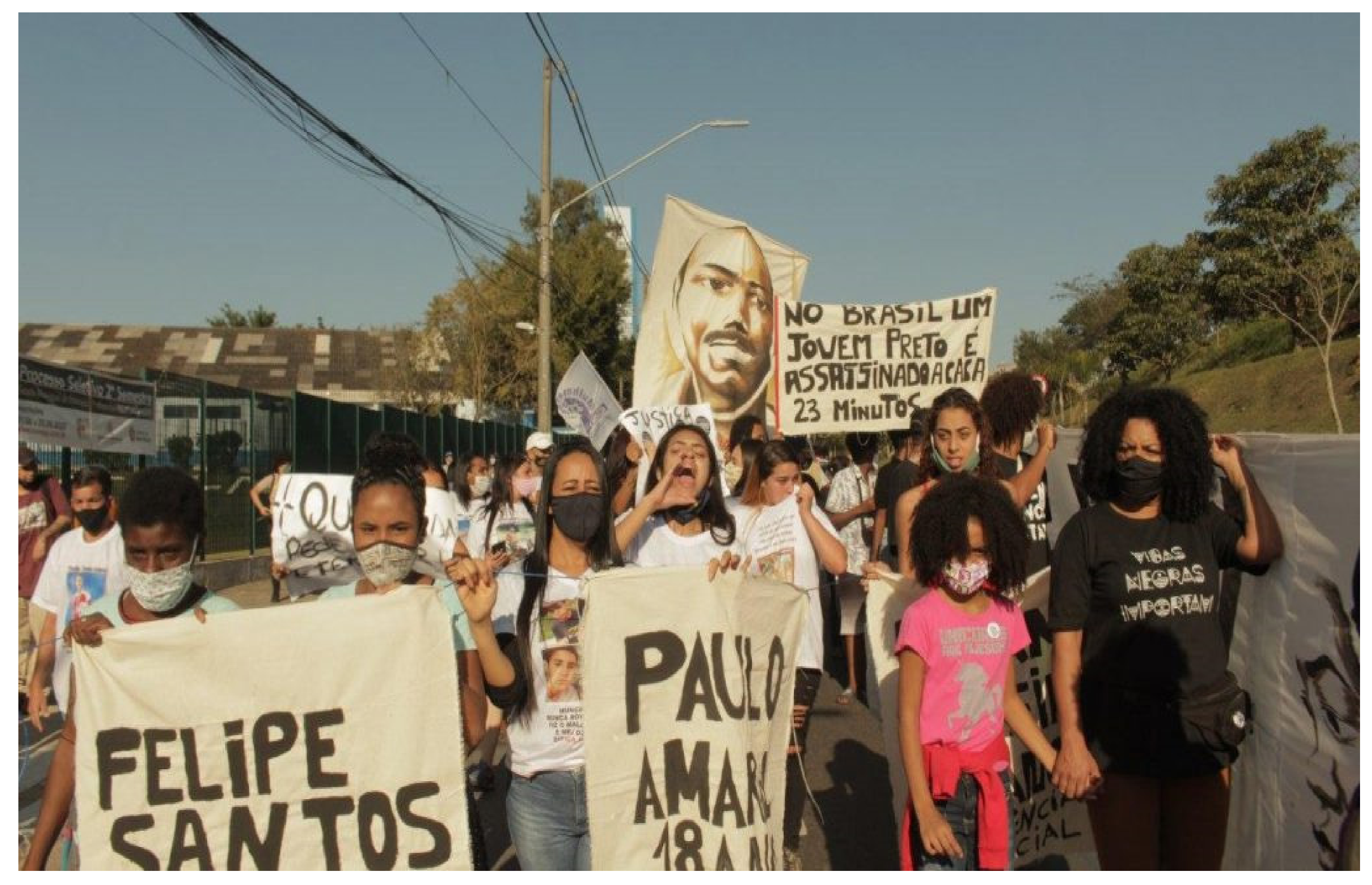

Foto 4 : Cidade Tiradentes Contra o Genocídio 


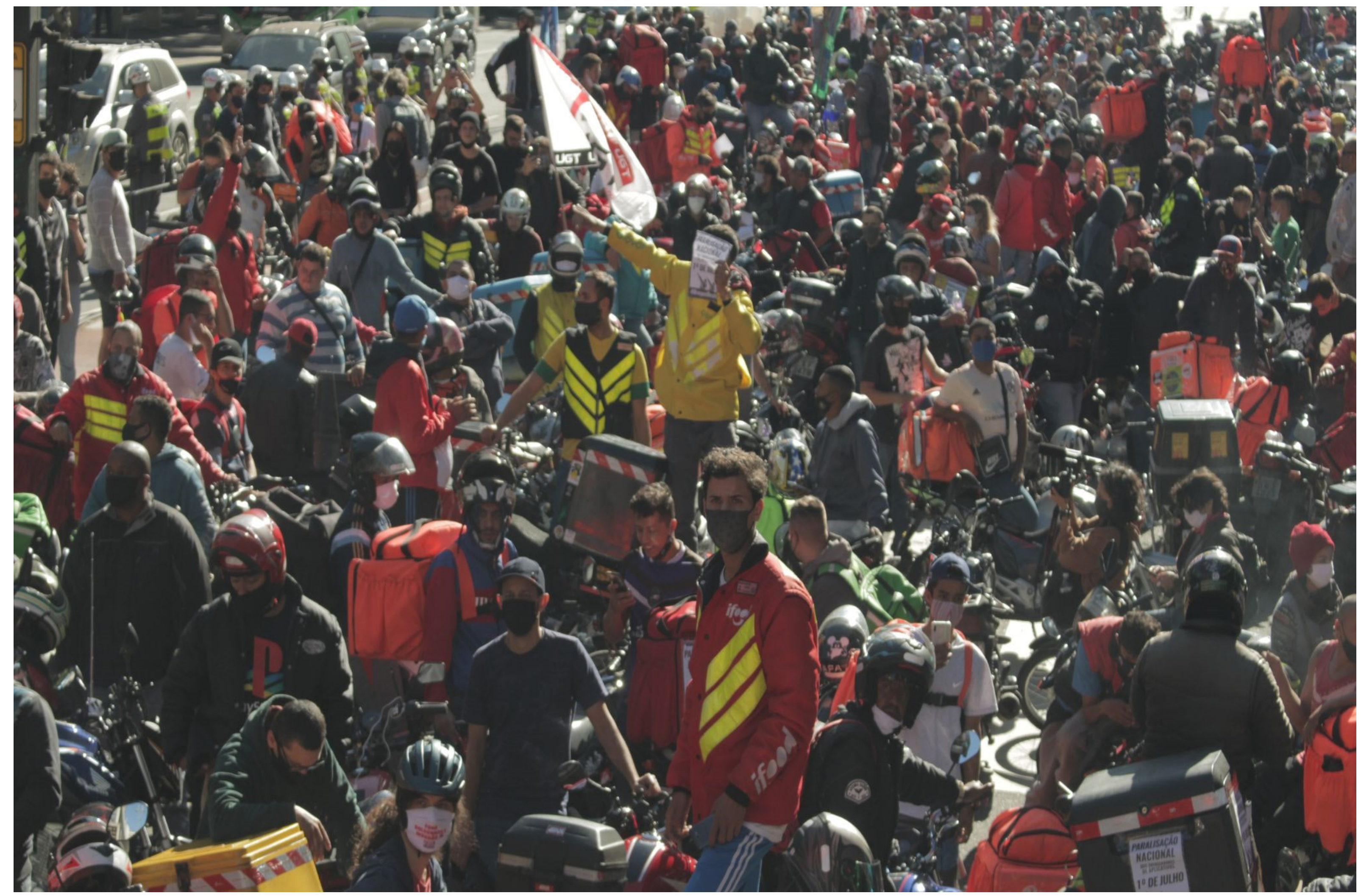

Foto 5: Breque do Apps 
Durante a pandemia, de forma inédita, entregadores e entregadoras de aplicativos pararam as motos e bicicletas em protesto por melhores condições de trabalho.

O processo de empresas que se articulam sobre a desregulamentação trabalhista no Brasil é conhecido como uberização na nova forma de acumulação do capital. A precarização das relações de trabalho remonta aos anos 70 frente à crise econômica estrutural do sistema capitalista que se acentua nas décadas seguintes. A larga utilização da tecnologia no mundo contemporâneo reestruturou as relações pessoais e as relações de trabalho na era dos aplicativos, com a criação de banco de dados pessoais dos usuários utilizados por empresas na publicidade e na política.

Os trabalhadores submetidos à utilização das bikes para entregas mediadas por aplicativos são, principalmente, jovens negros brasileiros. Pelo relatório produzido em 2019, em São Paulo, pela Associação Brasileira do Setor de Bicicletas, o "entregador ciclista de aplicativo (típico)" é "brasileiro, homem, negro, entre 18 e 22 anos de idade, morador das periferias com ensino médio completo, que estava desempregado e agora trabalha todos os dias da semana, de 9 a 10 horas por dia, com ganho médio mensal de $\mathrm{R} \$ 992,00$. O piso nacional do salário mínimo em 2019 era de $\mathrm{R} \$$ 998,00.

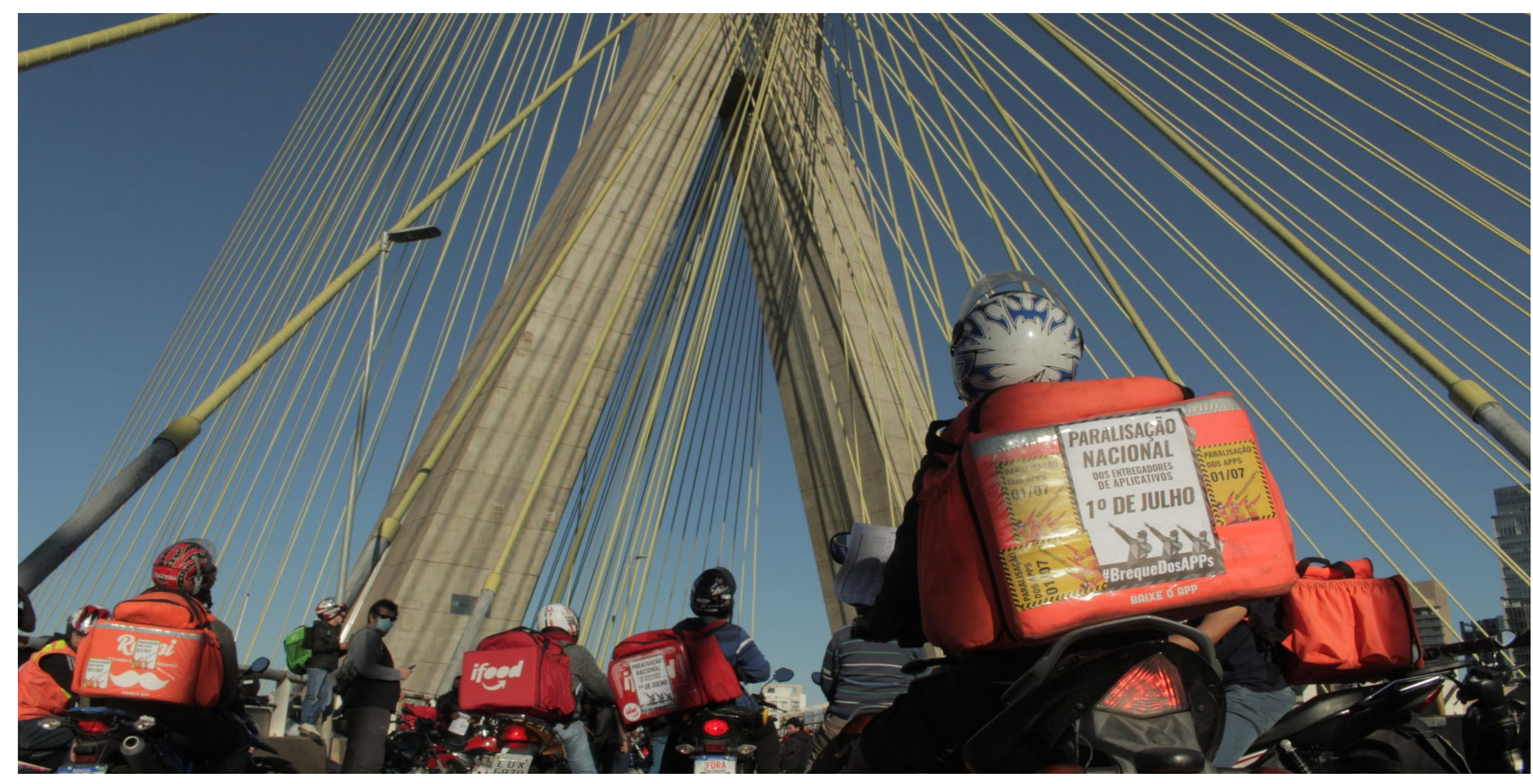

Foto 6: Breque Dos Apps 


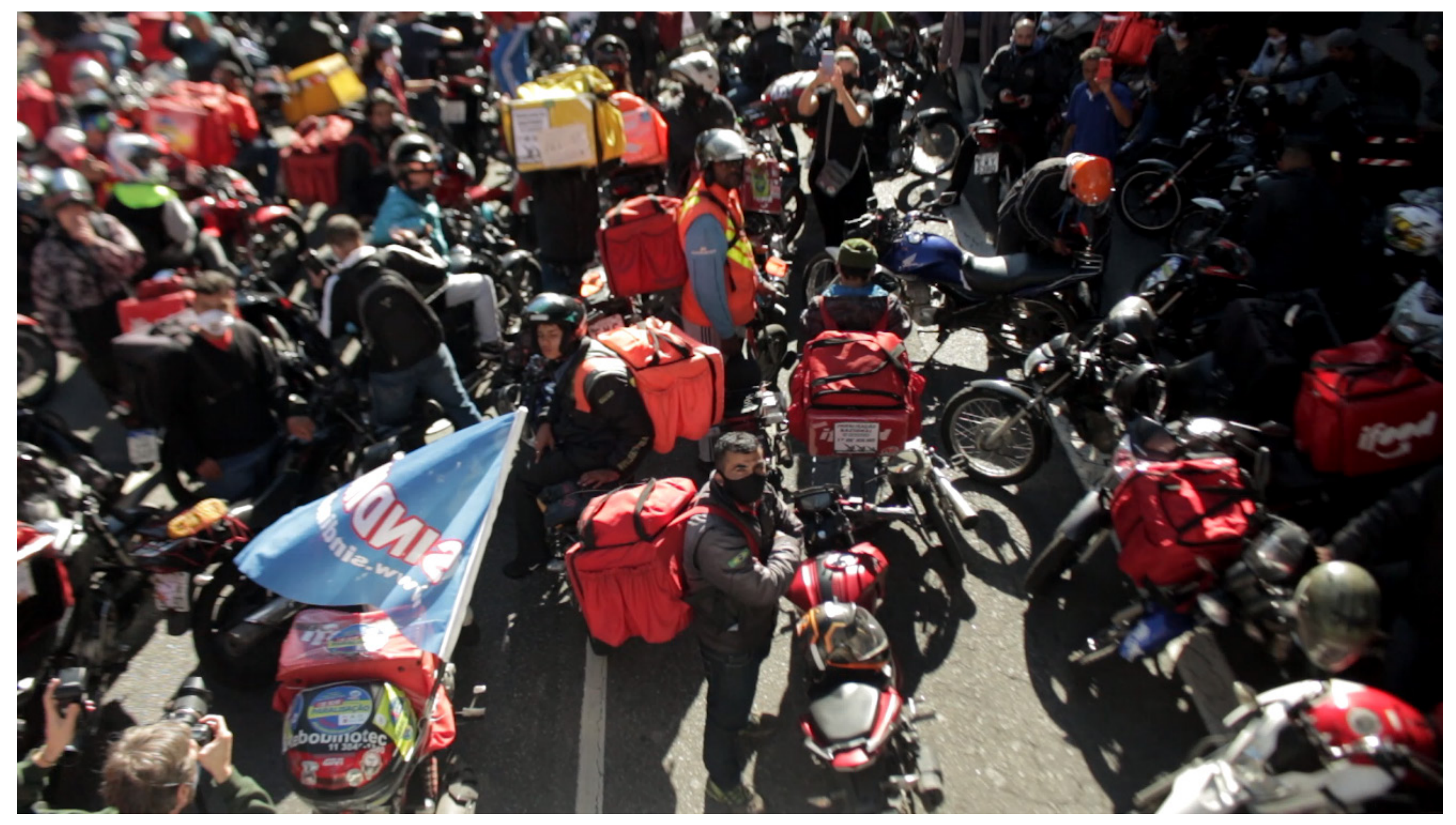

Foto 7: Breque Dos Apps 


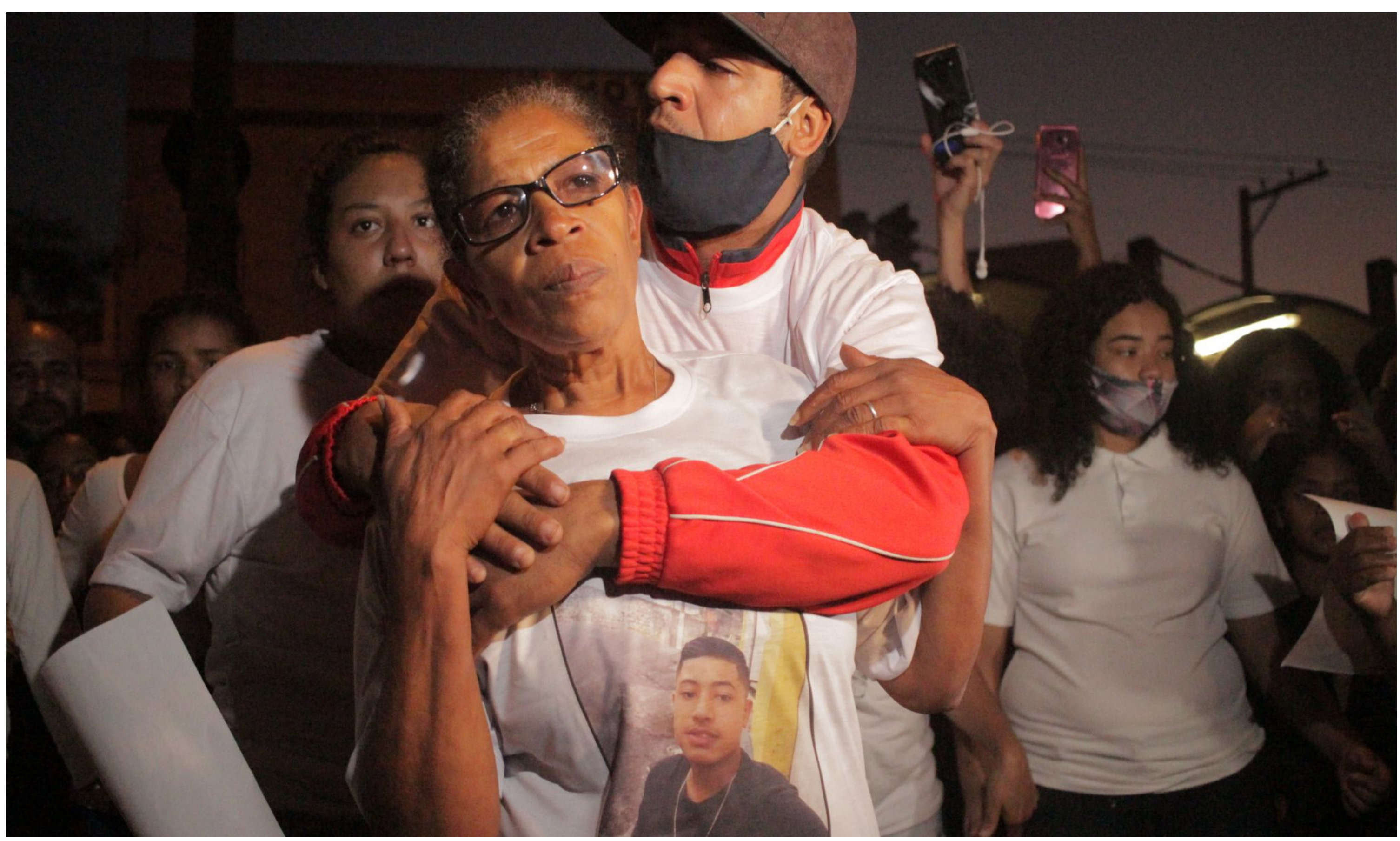

Foto 8 : Justiça por Guilherme 
"Ele saiu no portão só para olhar a rua antes de dormir. Chegaram dois malditos, tenho certeza que eram da polícia, e pegaram meu neto por engano", disse dona Toninha, avó do jovem Guilherme, de 15 anos, assassinado após ser rendido na porta de sua casa.

"Fui ver meu neto no cemitério com dois tiros na cabeça, muito machucado. Bateram muito nele. Ele não merecia. Mesmo que tivesse feito alguma coisa errada, nada justifica dar dois tiros na cabeça de um ser humano."
Dona Toninha participou do ato que aconteceu na Vila Clara, zona Sul de São Paulo. Foi realizada uma caminhada em repúdio à morte de Guilherme e também à repressão policial ocorrida em represália aos moradores no primeiro ato após o descobrimento do assassinato.

\section{CONTRA O GENOCÍDIO NEGRO, 07 de junho de 2020}

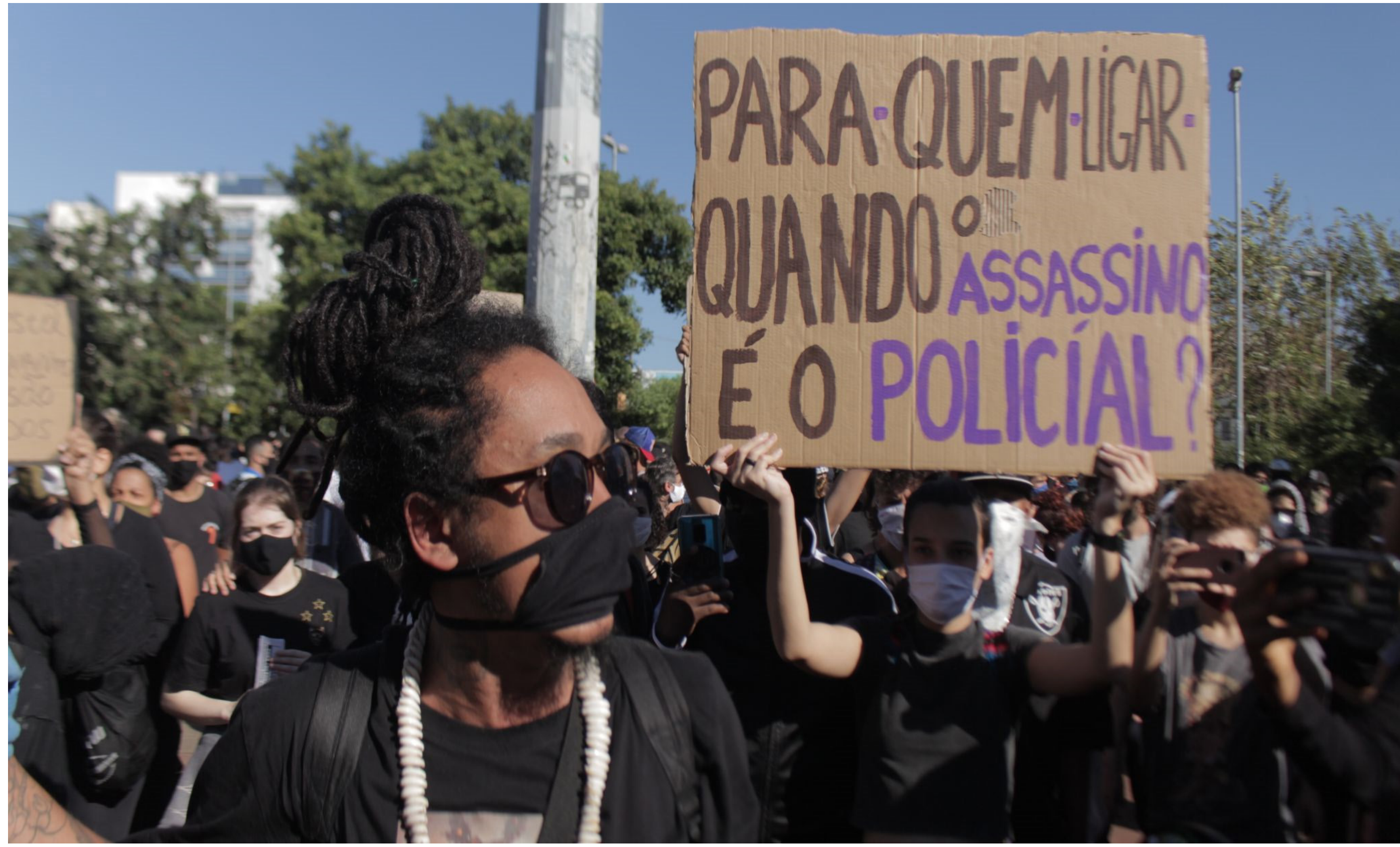

Foto 9: Contra o Genocídio Negro 
Após protestos mundiais em resposta ao assasinato de George Floyd, nos Estados Unidos, o Movimento Negro brasileiro se organizou em diferentes frentes de combate em um ponto de encontro comum: o Largo da Batata. Lá, além de George Floyd, foram lembrados casos de racismo estrutural da história recente do Brasil ocorridos antes e durante a pandemia.

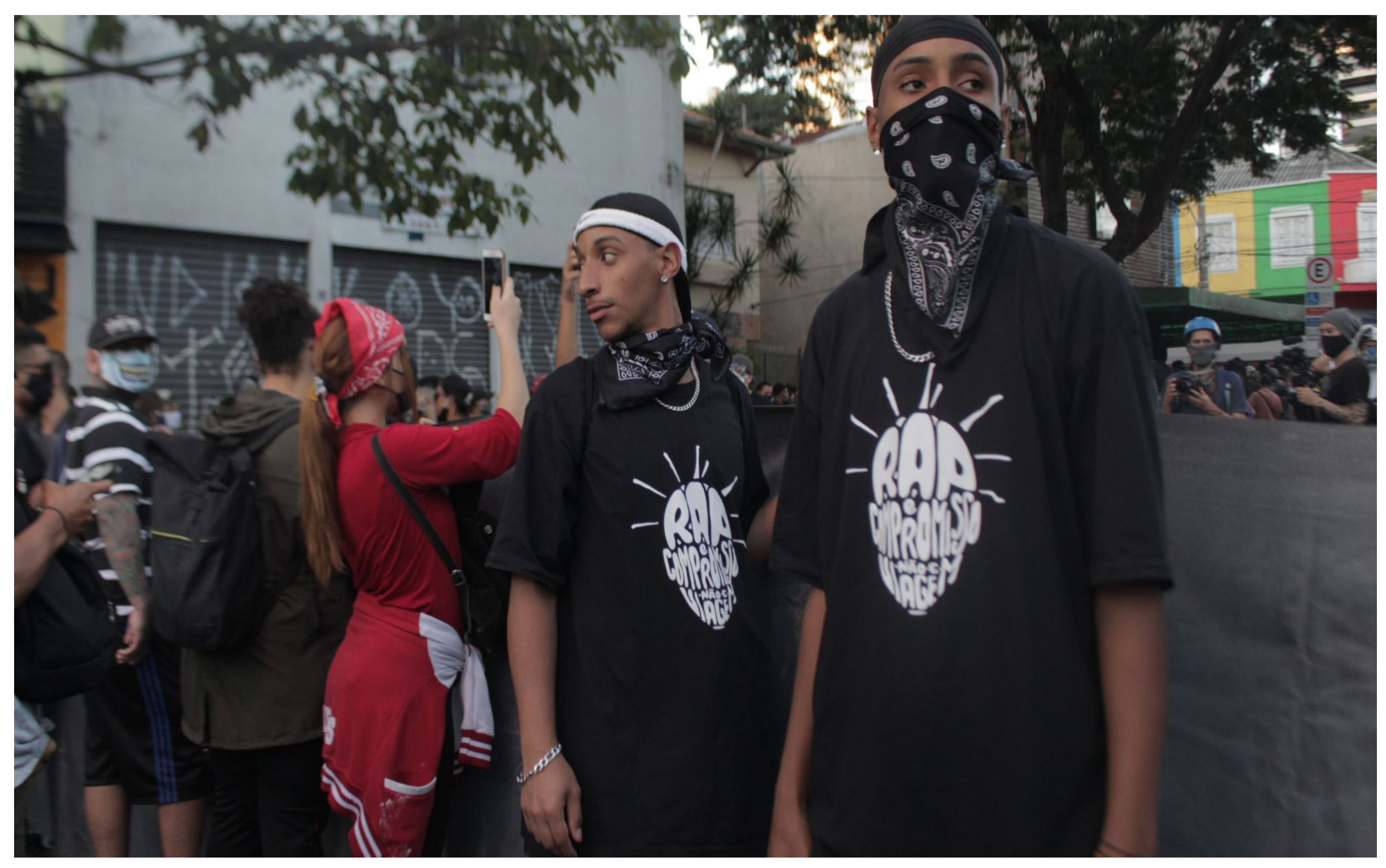

Foto 10: Contra o Genocídio Negro 